\title{
DEGRADAÇÃO AMBIENTAL DA BACIA HIDROGRÁFICA DO RIO UBERABA: UMA ABORDAGEM METODOLÓGICA ${ }^{1}$
}

\author{
HUMBERTO G. CANDIDO ${ }^{2}$, JOÃO A. GALBIATTI ${ }^{3}$, TERESA C. T. PISSARRA ${ }^{4}$, \\ MARCÍLIO V. MARTINS FILHO ${ }^{5}$
}

\begin{abstract}
RESUMO: O presente estudo trata da avaliação da degradação ambiental da bacia do Rio Uberaba, situada no triângulo mineiro, com área de 241.904,30 ha, abrangendo os municípios de Uberaba, Veríssimo, Conceição das Alagoas e pequena porção de Planura. Neste estudo, foi produzido o mapa de degradação ambiental contendo quatro níveis: baixo, moderado, acentuado e severo. Os parâmetros utilizados nesta avaliação foram: vegetação, topografia, solo/geologia, potencial natural de erosão, mecanização, área agrícola, densidade populacional, pecuarização e área de conflito, aos quais foram atribuídos pesos. Para o nível de degradação "baixo", foram definidos valores $\leq 13$ pontos. Para o nível "moderado", valores situados no intervalo de 14 a 16. Entre 17 e 19 pontos para o nível "acentuado", e o nível "severo" com valores $\geq 20$ pontos. Este estudo consolida as consequências do uso inadequado das terras, não respeitando a sua aptidão natural. As áreas com nível moderado de degradação representam 47\%, áreas de nível acentuado (48\%), e severo (4\%) representam 52\%, o que revela indício muito forte no avanço da destruição dos recursos naturais. As áreas classificadas com nível baixo representam apenas $1 \%$, bastante inexpressiva, destacando o descaso na preservação dos recursos naturais.
\end{abstract}

PALAVRAS-CHAVE: sistema de informação geográfica, geoprocessamento, vulnerabilidade.

\section{ENVIRONMENTAL DEGRADATION OF THE UBERABA RIVER WATERSHED: A METHODOLOGICAL BOARDING ${ }^{1}$}

\begin{abstract}
The present study is about the evaluation of the environmental degradation of the Uberaba river watershed situated in a region called Triângulo Mineiro. It possesses an area of 241,904.30 ha, which encloses the cities of Uberaba, Veríssimo, Conceição das Alagoas and a small portion of Planura. In this study the map of ambient degradation was produced containing four levels: low, moderate, accented and severe. The parameters used in this classification were: vegetation, topography, soil/geology, natural potential for erosion, mechanization, agricultural area, population density, cattle-raising and area of conflict for which it was attributed values. For "the low" level of degradation it was defined values $\leq 13$ points. For "the moderate" level, values situated in the interval of 14 to 16 . Values between 17 and 19 for "the accented" level, and "the severe" level with values $\geq 20$ points. This study consolidates the consequences of the inadequate use of land when it is not respected its natural aptitude. The areas with moderate level of degradation represent 47\%; however the areas of accented level (48\%) and severe (4\%) represent $52 \%$, what discloses a strong indication in the advance of the destruction of natural resources. The areas classified with low level represent only $1 \%$, sufficiently inexpressive, detaching the indifference in the preservation of natural resources.
\end{abstract}

KEYWORDS: system of geographic information, geoprocessing, vulnerability.

\footnotetext{
${ }^{1}$ Extraído da Tese de Doutorado do primeiro autor.

${ }^{2}$ Prof. Dr., DE, IFTM/UBERABA - MG, gois@iftriangulo.edu.br

${ }^{3}$ Prof. Titular, Departamento de Engenharia Rural, UNESP, Jaboticabal - SP, galbi@ fcav.unesp.br

${ }^{4}$ Profa. Dra., Departamento de Engenharia Rural, UNESP, Jaboticabal - SP, teresap@ @ fcav.unesp.br

${ }^{5}$ Prof. Dr., Departamento de Solos e Adubos, UNESP, Jaboticabal - SP, mfilho@ @fav.unesp.br

Recebido pelo Conselho Editorial em: 28-5-2008

Aprovado pelo Conselho Editorial em: 12-12-2009
}

Eng. Agríc., Jaboticabal, v.30, n.1, p.179-192, jan./fev. 2010 


\section{INTRODUÇÃO}

O Rio Uberaba é a principal fonte de abastecimento da cidade de Uberaba - MG, e no período da seca já não consegue atender à demanda. Esse fato vem agravando-se a cada ano devido aos impactos ambientais que estão ocorrendo ao longo de seu curso, especialmente pelo uso indiscriminado da irrigação.

CRUZ (2003), ao analisar mapas de uso dos solos de 1964 e 1998, verificou que a paisagem mudou bastante. A vegetação nativa que cobria mais de $40 \%$ da bacia, foi substituída principalmente por pastagens. Em boa parte das áreas que eram ocupadas por pastagens na década de 60, entre os municípios de Veríssimo e Conceição das Alagoas, houve substituição pela agricultura. Nas regiões de nascente, no município de Uberaba, a vegetação nativa foi substituída pela agricultura e por pastagens, agravando os impactos ambientais oriundos do modelo pelos quais foram exploradas essas terras.

O uso do geoprocessamento em conjunto com imagens de satélites, em estudos da degradação ambiental, são instrumentos extremamente úteis, pois permitem maior dinâmica no processo da geração das informações, possibilitando maior produtividade, rápida atualização e versatilidade no manuseio dos dados, conforme pode ser observado em relevantes trabalhos sobre degradação ambiental ou desertificação: BARBOSA et al. (2007), SÁ et al. (2006) e FEOLI et al. (2002).

Apesar da importância dos temas relacionados com a degradação/desertificação, as pesquisas ainda são muito limitadas no Brasil. Não existe um modelo metodológico padrão. Ao contrário, a diversidade metodológica é bastante expressiva. Consequentemente, a qualidade dos resultados desses trabalhos pode ser questionada. Destacam-se estudos realizados no Nordeste, incentivados principalmente pelas características ou condições do ambiente, como é o caso da desertificação. Os trabalhos desenvolvidos em nível local são poucos, predominando aqueles de caráter geral.

Considerando os constantes impactos ambientais que vêm ocorrendo ao longo dos tempos na bacia do Rio Uberaba, em especial, pelo atual avanço da monocultura (cana-de-açúcar), realizou-se este estudo com o objetivo de avaliar os reflexos desses impactos, tendo como um dos produtos principais o mapeamento da degradação ambiental, contribuindo, dessa forma, para a gestão e para o manejo sustentável da bacia.

\section{MATERIAL E MÉTODOS}

A área de estudo, situa-se na região do triângulo mineiro, abrangendo os municípios de Uberaba, Veríssimo, Conceição das Alagoas e pequena porção do município de Planura; apresenta área de 241.904,30 ha, sendo delimitada pelos paralelos $19^{\circ} 30^{\prime} 25^{\prime \prime} \mathrm{S} ; 2^{\circ} 07^{\prime} 46^{\prime \prime} \mathrm{S}$ e meridianos $47^{\circ} 39^{\prime} 00^{\prime \prime} \mathrm{W} ; 48^{\circ} 34^{\prime} 45^{\prime \prime} \mathrm{W}$.

Os materiais utilizados foram imagens multiespectrais do satélite CBERS-2 (Satélite Sino-Brasileiro de Recursos Terrestres), sensor CCD, órbita/ponto 156/122 e 157/122, bandas 2; 3 e 4, com resolução espacial de $20 \mathrm{~m}$, obtidas em: 10-3-2007 para as cenas 156/122; e 2-4-2007 para as cenas 157/122 (época chuvosa); 8-9-2007 para as cenas 156/122; e 5-9-2007 para as cenas 157/122 (época seca), CBERS-2 CCD (2007); GPS Garmin 12XL, sistema de informação geográfica SPRING 5.0, e mapas temáticos: mapa do potencial natural de erosão - PNE; classes de declividade; solos; uso atual das terras, e mapa de conflito de uso das terras.

A seguir, são destacadas as etapas do processo de avaliação da degradação ambiental.

\section{Análise visual das imagens orbitais CBERS-2}

A metodologia para interpretação visual de imagens orbitais utilizada neste estudo é baseada na técnica de fotointerpretação de fotografias aéreas, adaptada à análise de imagens LANDSAT, elaborada por VENEZIANI \& ANJOS (1982). 
Nessa etapa, foi produzido o mapa com as zonas homólogas, no total de 132, baseado nos parâmetros tonalidade de cinza, textura fotográfica, relevo, vegetação e grau de intensidade de uso das terras.

As imagens de satélite foram utilizadas como base para orientação, espacialização e diagnose preliminar das áreas com diferentes níveis de degradação.

Para a confecção das zonas homólogas, montou-se a composição colorida B2-R3-G4, formando um mosaico com as imagens do satélite CBERS-2. Por meio do sistema de informação geográfica SPRING, criou-se a categoria temática "degradação", por meio do comando "modelo de dados," contendo quatro classes temáticas: "baixo", "moderado", "acentuado" e "severo". Para essas classes, atribuíram-se cores: oliva (amarelo-escuro); cáqui (amarelo); laranja-escuro e urucum (vermelho-escuro), respectivamente.

$\mathrm{Na}$ categoria "degradação", criou-se o PI (plano de informação), temático, "zonas homólogas", por meio do comando "plano de informação", sem classes temáticas, exclusivo para a confecção das zonas homólogas.

As zonas homólogas foram produzidas por meio da digitalização sobre o mosaico de imagens de satélite CBERS-2, produzindo, assim, um plano de informação vetorial, que serviu como base para a análise da degradação ambiental, sobrepondo esse PI sobre os mapas de uso atual, declividade, solo, potencial natural de erosão, área de conflito e o mosaico de imagens CBERS-2 do período seco, para facilitar a análise da vegetação, especialmente a nativa.

\section{Determinação dos níveis de degradação ambiental}

Neste estudo, procurou-se resgatar trabalhos pioneiros, especialmente os realizados por grupos de pesquisadores, em que foi utilizada grande diversidade de parâmetros na avaliação da degradação ambiental.

$\mathrm{Na}$ determinação dos níveis de degradação ambiental, foram agrupadas partes das metodologias utilizadas por FERREIRA et al. (1994), ITDG (1994), BAUMGRATZ \& BOAVENTURA (1986) e EMBRAPA (1994), adaptadas por CANDIDO et al. (2002) para trabalhos em escalas de semidetalhe (1:100.000).

As consequências dos impactos gerados pelas ações antrópicas, ao longo do tempo na bacia, foram avaliadas por meio dos parâmetros ou indicadores: vegetação, topografia, solo/geologia, potencial natural de erosão-PNE, mecanização, área agrícola, densidade populacional, pecuarização e área de conflito, para os quais foram atribuídos pesos em função dos seus impactos ou importância para o ambiente. Quanto maior for o peso, maior será o impacto no ambiente.

A soma total dos pesos de cada indicador ou parâmetro, para cada uma das 132 zonas homólogas analisadas, é de 29 pontos, sendo o máximo que se pode atingir por zona. Para o nível de degradação "baixo", foram adotados valores menores ou iguais a 13 pontos. Para o nível "moderado", consideraram-se os valores situados no intervalo de 14 a 16 . As zonas com peso de 17 a 19 pontos foram classificadas como nível "acentuado", e as com pesos maiores ou iguais a 20 pontos, como nível de degradação ambiental "severo".

\section{Checagem de campo para a avaliação complementar da vulnerabilidade ambiental}

O trabalho de campo foi realizado por meio do reconhecimento geral da área, seguindo roteiro preestabelecido e de acordo com as unidades morfológicas previamente reconhecidas nas imagens orbitais.

Nessa etapa, realizou-se o trabalho de verificação da verdade terrestre. Também foram colhidos dados complementares e essenciais para o ajuste na avaliação dos parâmetros, tais como: informações detalhadas sobre o relevo, a vegetação, erosões, uso do solo, etc. O GPS foi utilizado na locação ou georreferenciamento dos pontos estudados, principalmente os locais de maior impacto ambiental. A máquina fotográfica teve grande utilidade por possibilitar o registro de dados 
importantíssimos, como, por exemplo: assoreamentos, fontes de poluição, vista panorâmica da área, etc., que auxiliaram bastante na análise final da degradação ambiental.

\section{Elaboração do mapa final de degradação ambiental}

De acordo com os parâmetros anteriormente propostos e com os dados de avaliação observados no campo, utilizou-se o SPRING que, por meio da edição vetorial, efetuou o ajuste ou a correção das áreas classificadas em desacordo com a realidade do ambiente da bacia; concluindo, portanto, o mapa final de degradação ambiental, composto pelos níveis: baixo, moderado, acentuado e severo.

\section{RESULTADOS E DISCUSSÃO}

\section{Análise dos parâmetros}

O mapa de zonas homólogas (Figura 1) foi utilizado como estrutura-padrão de análise das áreas identificadas por números (zonas homólogas ou áreas com características semelhantes). Esse foi sobreposto aos mapas temáticos. No caso do mapa de solos, foram extraídas informações sobre o potencial agrícola, destacando-se a qualidade ou a fertilidade natural das terras. Nesse caso, foram consideradas três situações em função da qualidade das terras: terras boas para plantar, peso 1; terras regulares para o plantio, peso 2; terras inadequadas, peso 3. Quanto maiores forem os pesos, maiores serão as limitações das terras ou sua capacidade de suporte na produção de alimentos.

No mapa de solos (Figura 2), tem-se como exemplo a zona homóloga 22; pelos critérios de avaliação, o solo classificado (predominante) é o Latossolo Vermelho distroférrico, em que se obteve peso 2 (terras regulares para plantio). Como as zonas homólogas foram construídas baseadas em imagens de satélites, o critério adotado para a análise dos demais mapas temáticos, inclusive o mosaico de imagens orbitais, foi considerar o elemento ou fator de maior expressão ou dominância em cada zona homóloga.

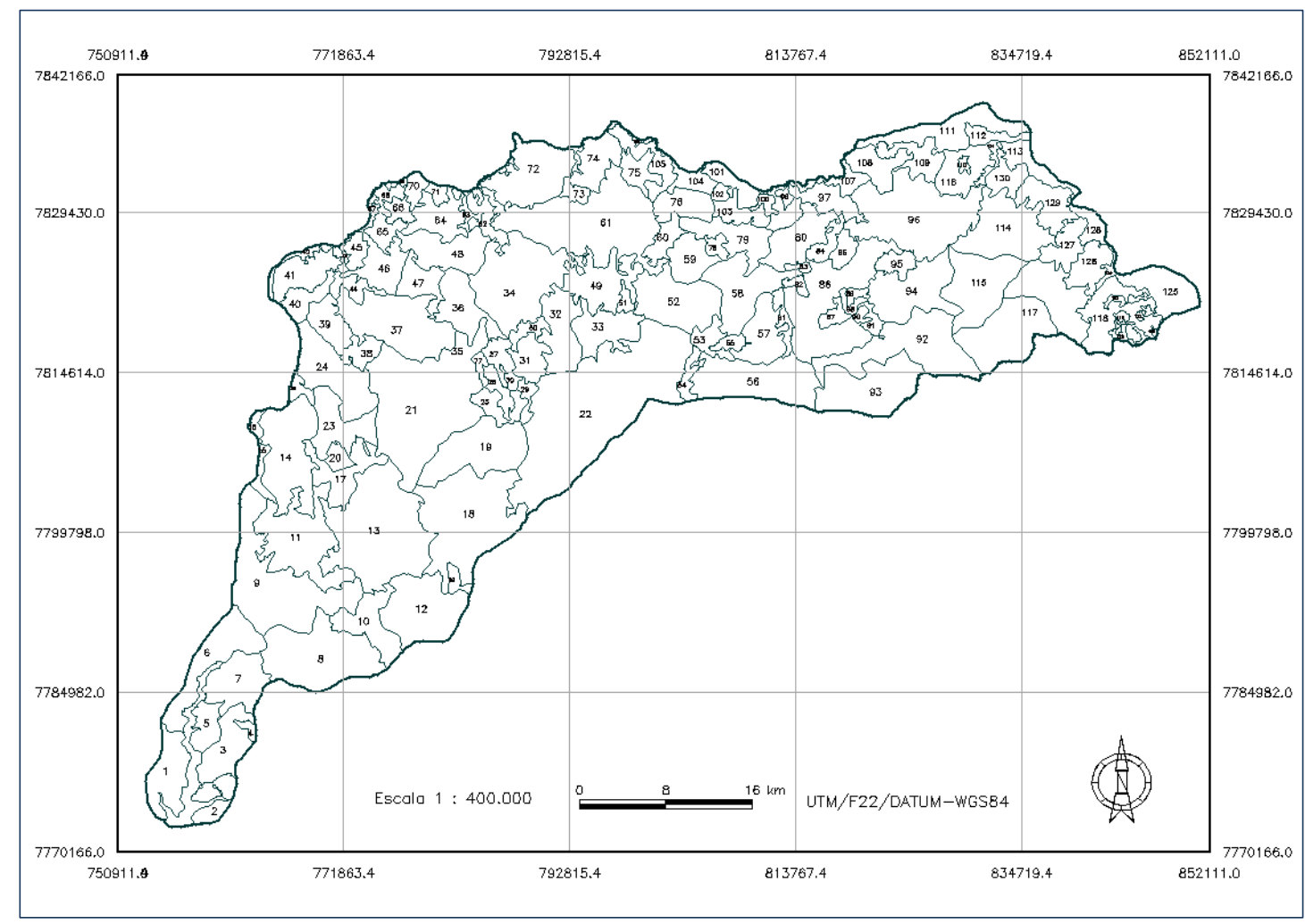

FIGURA 1. Mapa das zonas homólogas. Map of homologous zones. 


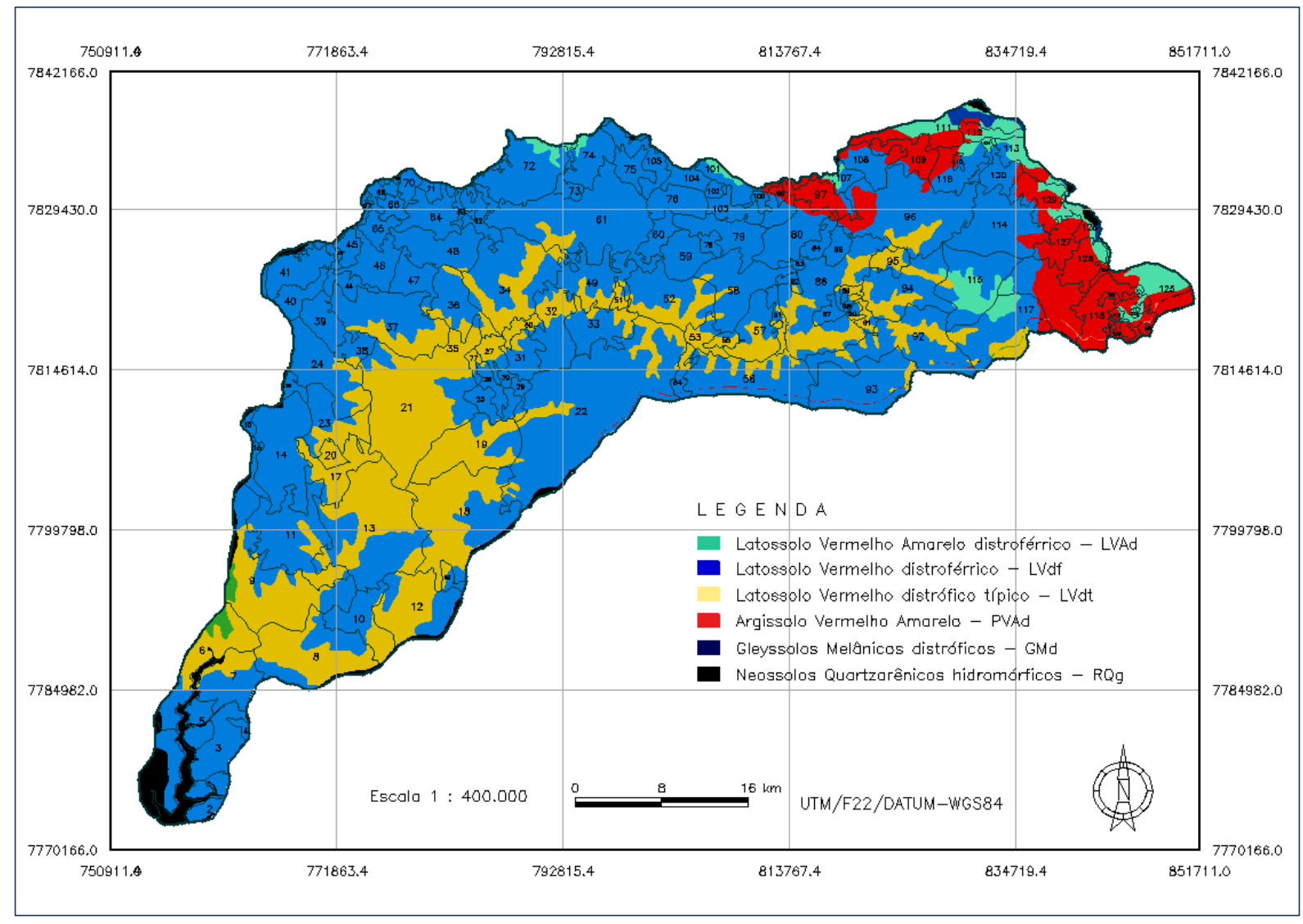

FIGURA 2. Mapa de solos da bacia do Rio Uberaba. Soil map of Uberaba River basin (VALLE JÚNIOR, 2008).

Os impactos na cobertura vegetal original, provocados pelas ações antrópicas, foram um dos primeiros fatores responsáveis pelo desenvolvimento do processo de degradação das terras, especialmente pela ação que exerce na proteção do solo contra os efeitos erosivos. Na análise da vegetação, seis níveis ou situações foram considerados, uma vez que, quanto menor for a cobertura vegetal presente na zona homóloga, maior será o peso: vegetação fechada, peso 1; densa, peso 2; semi-densa, peso 3; aberta, peso 4; rala, peso 5, e muito rala, peso 6; portanto, é o parâmetro mais representativo ou de maior peso na avaliação da degradação ambiental. Analisou-se a cobertura vegetal nativa, utilizando-se do mosaico de imagens CBERS-2 da estação seca, onde foi observada cobertura vegetal bastante pobre (Figura 3).

O mosaico de imagens CBERS-2 também foi utilizado na avaliação do parâmetro densidade populacional, o qual foi subdividido em três níveis: $<15$ hab km², peso $1 ; 15$ a $30 \mathrm{hab} \mathrm{km}^{-2}$, peso 2; $>30 \mathrm{hab} \mathrm{km}^{-2}$, peso 3. Nesse caso, foi considerada a concentração de moradias, ou a sua inexistência nas zonas homólogas, sendo a classificação efetuada por estimativa.

O potencial natural de erosão (PNE) é obtido a partir da integração de dados dos fatores da EUPS (equação universal de perdas de solo), que se refere aos elementos do meio físico, considerando a erosividade da chuva, erodibilidade do solo e fator topográfico. Assim, o mapa do potencial natural de erosão (Figura 4) é um substancial fator na análise da vulnerabilidade ambiental, destacando-se três níveis: baixo risco de erosão, peso 1; médio risco de erosão, peso 2, e alto risco de erosão, peso 3 . 


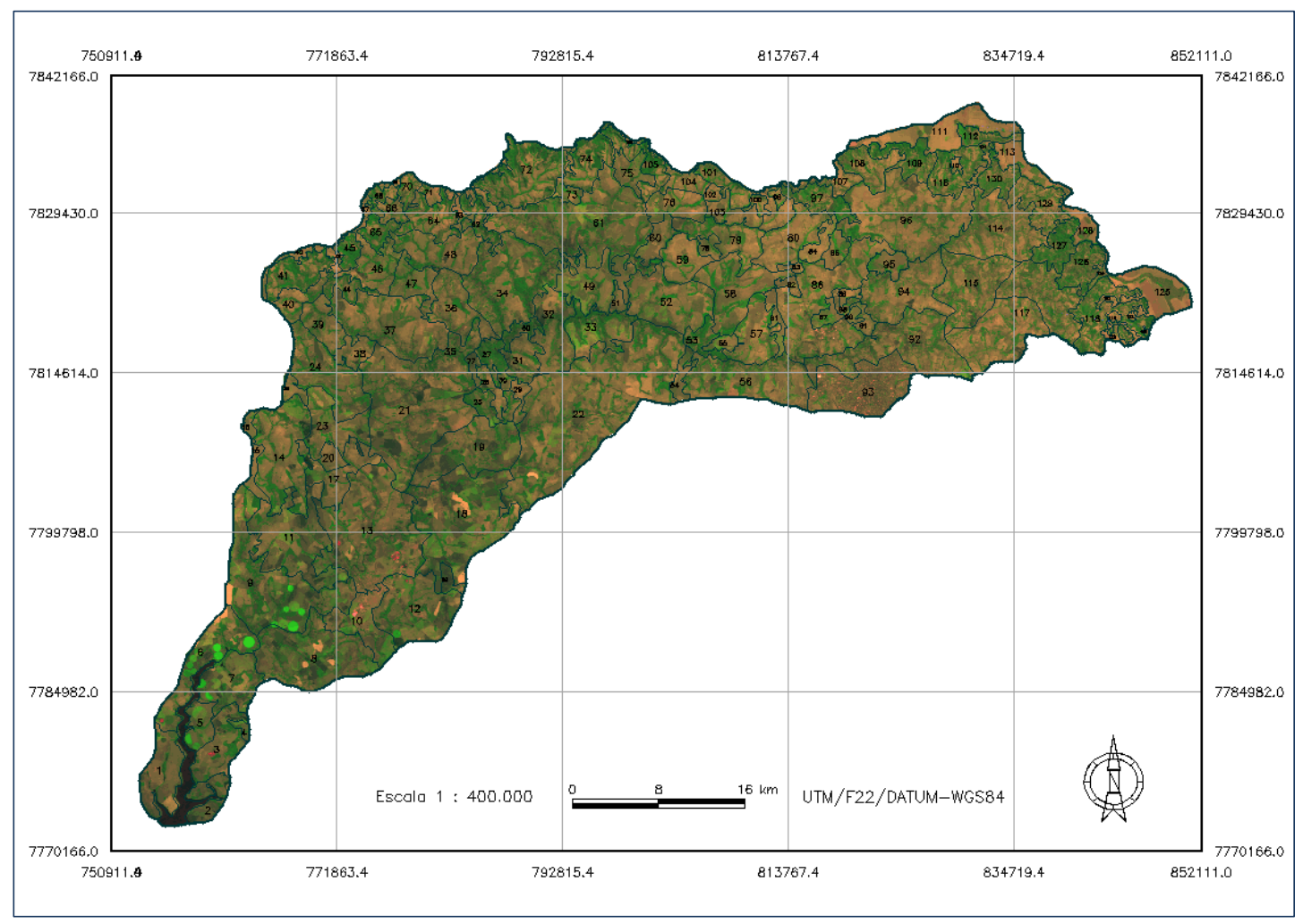

FIGURA 3. Mosaico do satélite CBERS-2. Composição colorida B2-R3-G4. Época seca. Mosaic of the CBERS-2 satellite. Colored composition B2-R3-G4. Dry season.

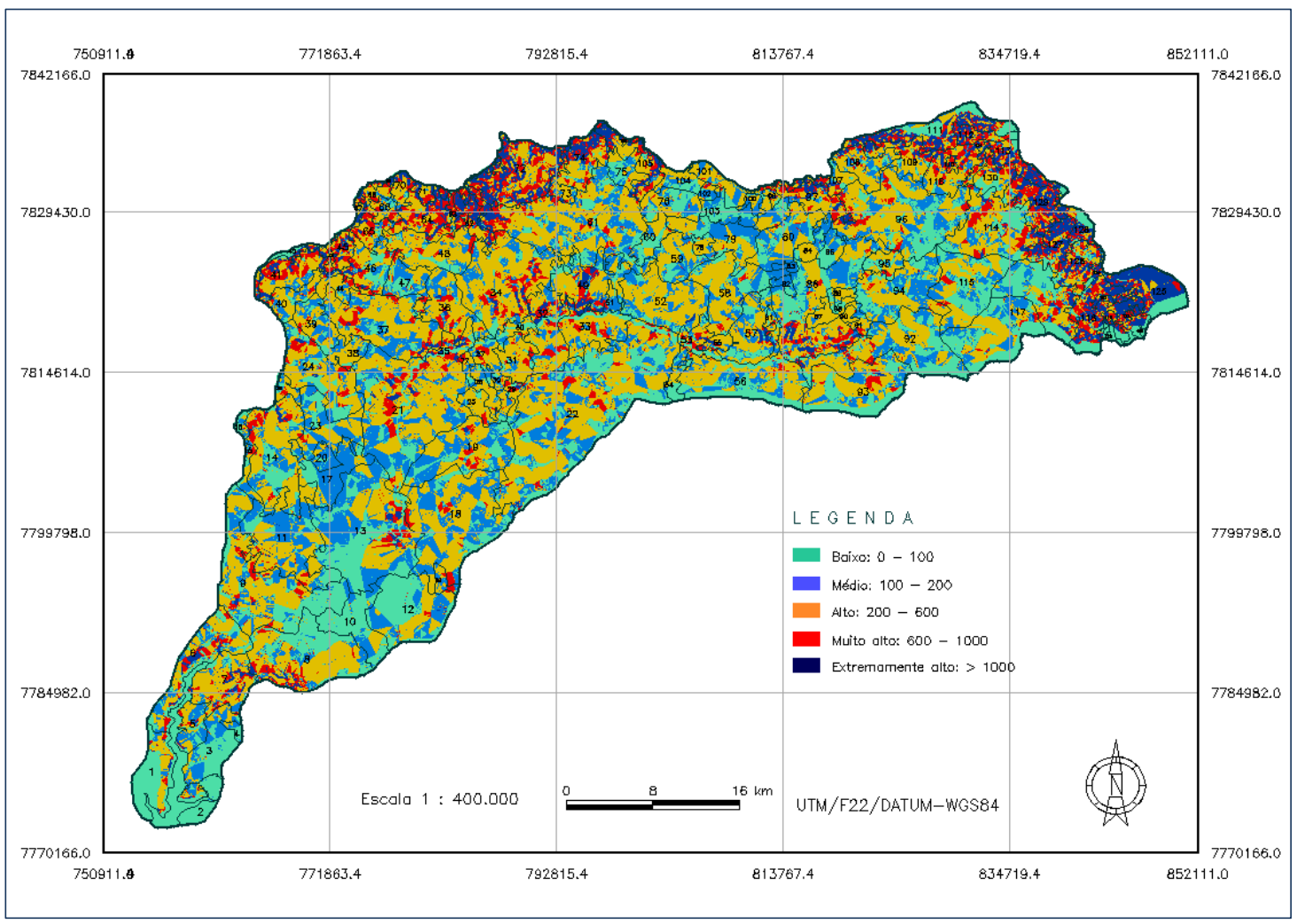

FIGURA 4. Mapa do potencial natural de erosão - PNE. Map of natural erosion potential (VALLE JÚNIOR, 2008). 
Em pesquisa realizada por CRUZ (2003) na área de estudo, as áreas de relevo plano a ondulado (declives entre 0 a 10\%) ocupam praticamente toda a extensão da bacia (90,3\%), predominando as baixas declividades. Declives entre 10 e $20 \%$ correspondem a $8 \%$ da área; e declives acima de $20 \%$ são áreas de relevo montanhoso escarpado, ocupando apenas 1,7\% da bacia.

A topografia (Figura 5) é um fator bastante expressivo na estabilidade do ambiente, a exemplo da vegetação, tendo participação muito significativa nos processos de degradação ambiental. Esse parâmetro foi distribuído em cinco níveis de declividade, acompanhados dos seus respectivos pesos: declives de 0 a $5 \%$, peso 1 ; declives de 5 a $10 \%$, peso 2; declives de 10 a $20 \%$, peso 3; declives de 20 a $47 \%$, peso 4; e declives acima de $47 \%$, peso 5 .

As áreas com declives acima de $47 \%$ são muito pequenas e pontuais, e apesar de existirem, não foram classificadas em nenhuma das zonas homólogas, em função dos critérios adotados neste trabalho (o fator de maior expressão, ou declive predominante na zona homóloga analisada).

Conforme ROCHA \& KURTZ (2001), os conflitos de uso das terras são os maiores responsáveis pelas erosões, assoreamentos de rios, barragens, açudes, enchentes e efeitos das secas. Os conflitos são consequências do uso incorreto dos solos, não respeitando a aptidão agrícola ou a capacidade de uso das terras, como, por exemplo, o cultivo agrícola em terras de classes de capacidade de uso V, VI, VII e VIII; a pecuária desenvolvida em áreas de classe de uso VII e VIII, ou o cultivo agrícola em terras apropriadas, porém com declividade média acima de $10 \%$, sem adoção de práticas de conservação do solo.

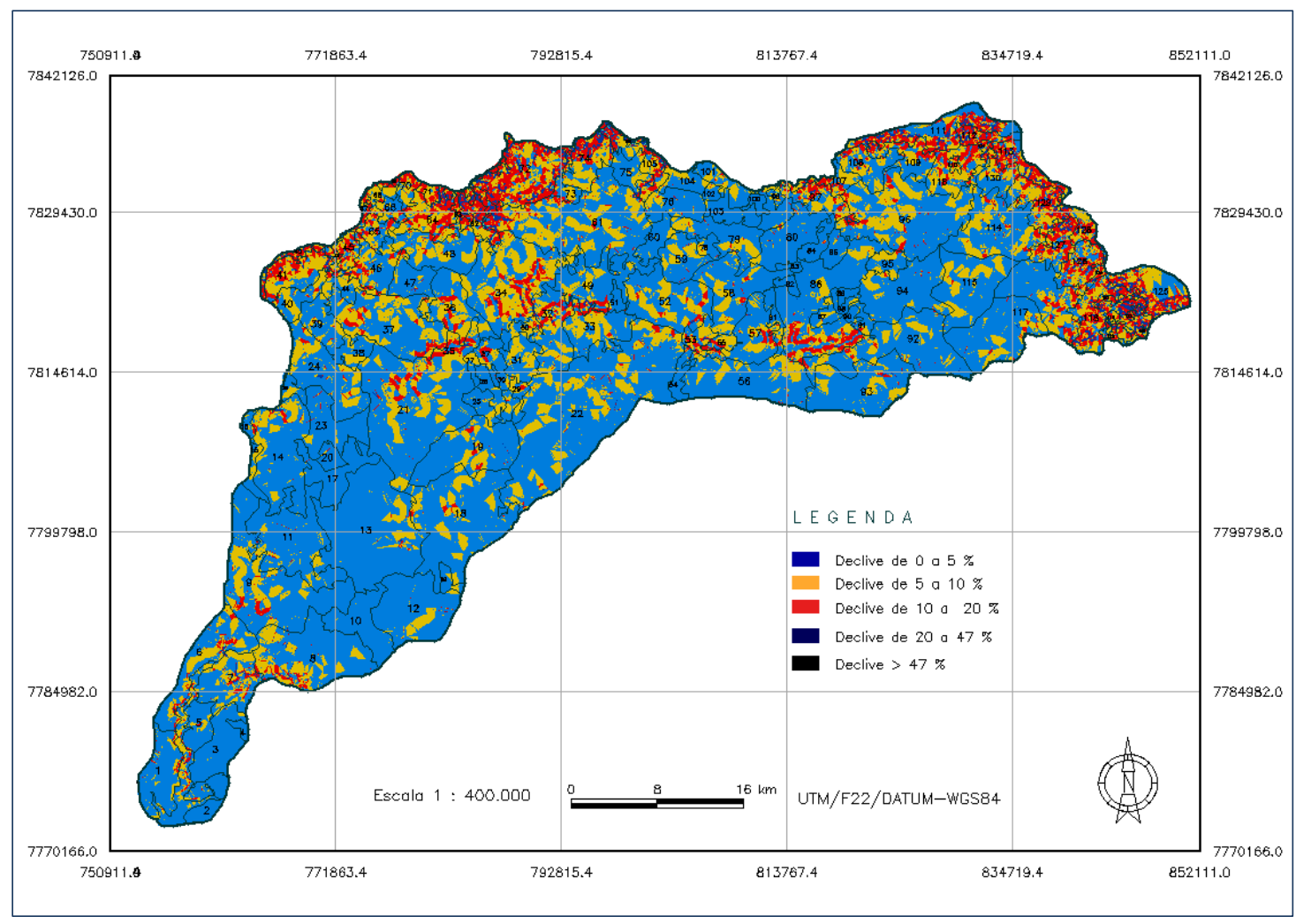

FIGURA 5. Mapa de declividades. Map of declivities (VALLE JÚNIOR, 2008).

TORRES et al. (2007) constataram conflitos de uso do solo na microbacia do Córrego Lanhoso (microbacia do Rio Uberaba). Nessa área, a legislação ambiental vem sendo desrespeitada, pois as áreas de pastagens estão à beira do córrego, onde se observa o seu assoreamento. Nas áreas de classe VI e VIII, foram encontrados locais de deposição de lixo, prática conflitante com os possíveis usos da área, tornando-se foco de poluição. 
Um exemplo típico de conflito de uso do solo, existente na área da bacia do Rio Uberaba, é destacado na Figura 7, na qual a cultura da cana-de-açúcar avança até as áreas de nascente.

O parâmetro "área de conflito" foi adotado por considerar que as áreas de uso do solo em conflito (Figura 6) são áreas onde os efeitos dos impactos são maiores ou mais danosos ao ambiente. Foram consideradas três situações de conflito de uso do solo. O peso foi definido em função do percentual de ocorrência de conflito em cada zona homóloga: sem conflito, peso 1; menor que $50 \%$, peso 2; áreas com ocorrência maior que $50 \%$, peso 3 .

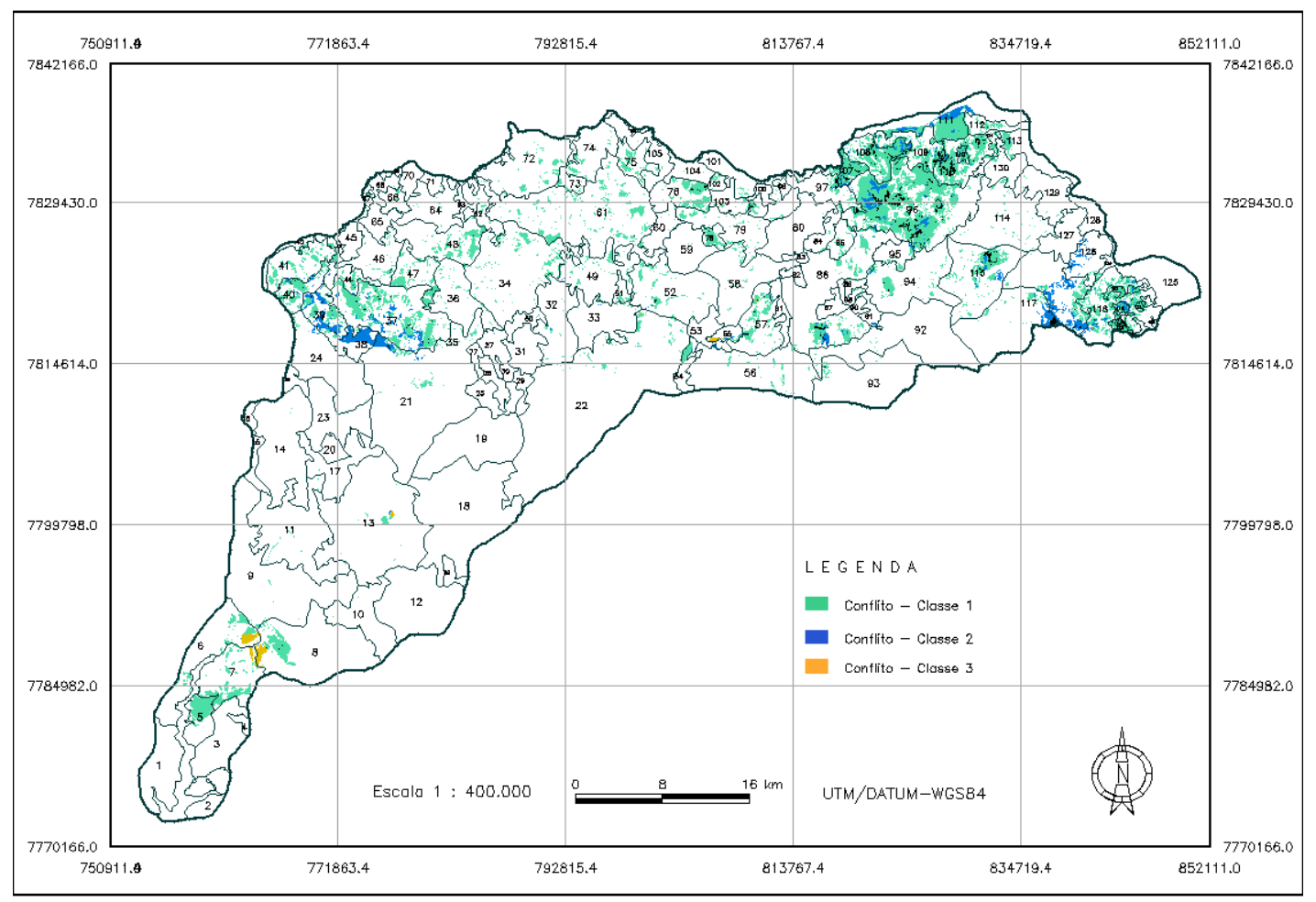

FIGURA 6. Mapa de conflito de uso da terra. Map of land use conflict (VALLE JÚNIOR, 2008).

As análises dos parâmetros mecanização, pecuarização e área agrícola foram realizadas tendo como base o mapa de uso do solo de 2008 (Figura 8). Esse foi subdividido em dois níveis: áreas de cultivo menor que $50 \%$, peso 1 ; área agrícola maior que $50 \%$, peso 2 . No parâmetro mecanização, considerou-se o seu uso na zona homóloga analisada, adotando-se peso 1 para ausência de mecanização e peso 2 para a existência de mecanização, tendo como base as áreas agrícolas, em especial, as culturas em que se utiliza de muita mecanização, como no caso da soja e da cana. No parâmetro pecuarização, considerou-se a sua presença ou não na zona homóloga, em que se adotou o peso 1 para ausência de pecuarização e peso 2 para a sua existência.

Os resultados da Tabela 1 (somatório geral) correspondem ao grau de vulnerabilidade de cada zona homóloga. O valor máximo que se pode obter, nos pesos, em cada zona homóloga, é vinte e nove, e o mínimo, de nove pontos. Estes resultados foram utilizados no SPRING para elaboração do mapa de degradação ambiental.

Por meio da edição vetorial no SPRING, associou-se cada zona homóloga, em função do peso encontrado, às classes previamente determinadas (Tabela 2). 


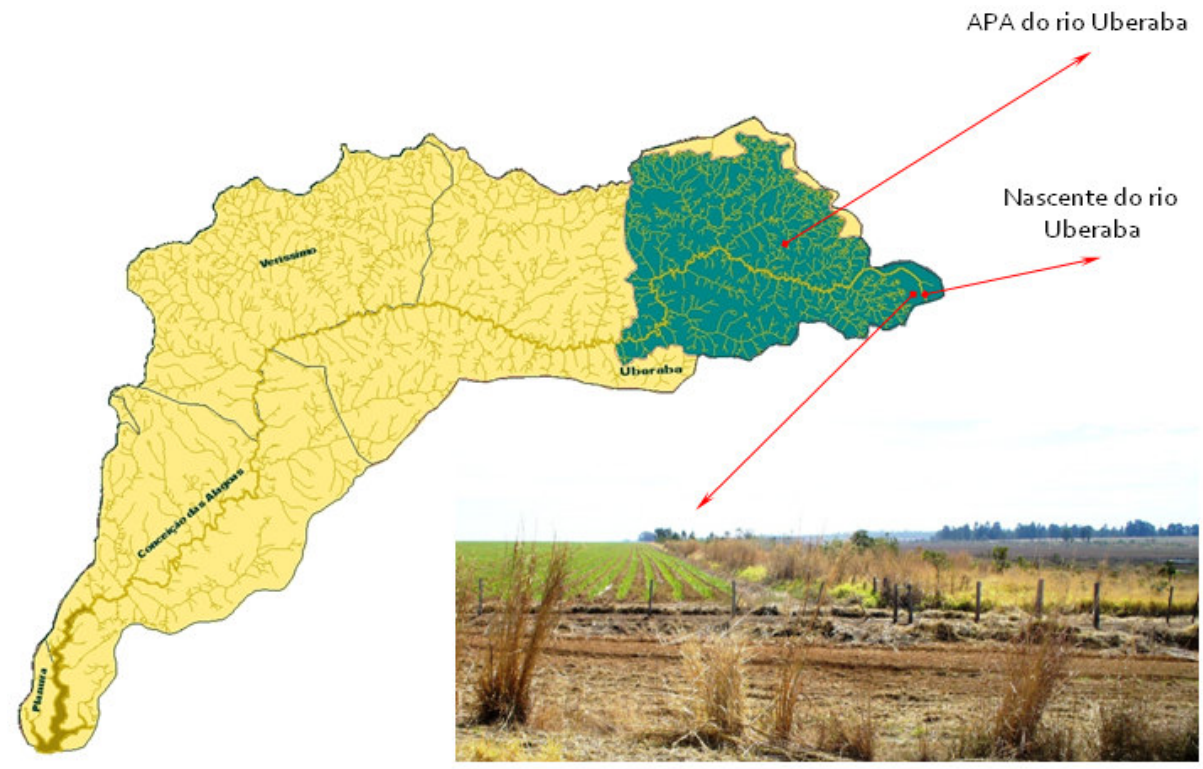

FIGURA 7. APA do Rio Uberaba. Em detalhe: cultivo de cana-de-açúcar próximo à nascente do Rio Uberaba. APA of the Uberaba River. In detail: cultivation of sugarcane near the source of the Uberaba River.

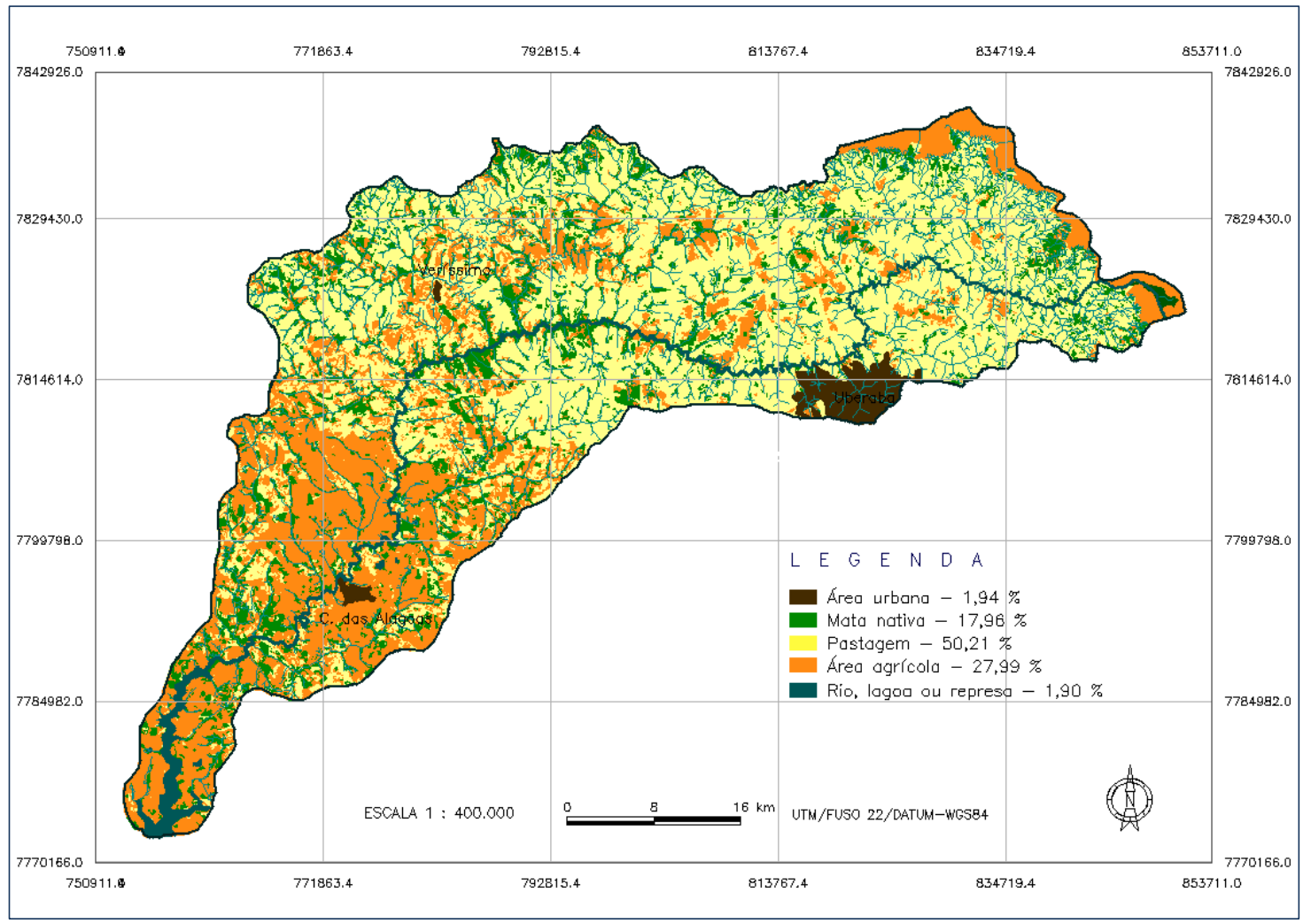

FIGURA 8. Mapa de uso atual das terras - 2008. Map of current land use - 2008. 
TABELA 1. Avaliação da vulnerabilidade ambiental das zonas homólogas. Environmental vulnerability evaluation of homologous zones (CANDIDO et al., 2002).

\begin{tabular}{|c|c|c|c|c|c|c|c|c|c|c|c|c|c|c|c|c|c|c|c|c|}
\hline \multicolumn{21}{|c|}{ *Avaliação da Vulnerabilidade Ambiental das Zonas Homólogas } \\
\hline Indicadores & & & & & Zo: & las & Iom & blog & as - & Pes & En & con & rad & & & & & & & \\
\hline \multirow{7}{*}{ Vegetação } & Peso & $\begin{array}{c}\text { Dados } \\
\text { (níveis) }\end{array}$ & 1 & 2 & 3 & 4 & 5 & 6 & 7 & 8 & 9 & 10 & 11 & 12 & 13 & 14 & 15 & 16 & 17 & 18 \\
\hline & 6 & Muito rala & 6 & & & & & & & & & & & & & & & 6 & & \\
\hline & 5 & Rala & & 5 & 5 & & & & & & & & & & & & & & 5 & \\
\hline & 4 & Aberta & & & & & 4 & 4 & 4 & 4 & & 4 & 4 & 4 & 4 & & 4 & & & \\
\hline & 3 & Semidensa & & & & & & & & & 3 & & & & & 3 & & & & 3 \\
\hline & 2 & Densa & & & & 2 & & & & & & & & & & & & & & \\
\hline & 1 & Fechada & & & & & & & & & & & & & & & & & & \\
\hline \multirow{6}{*}{ Topografia } & Peso & Dados (\%) & & & & & & & & & & & & & & & & & & \\
\hline & 1 & $0-5$ & 1 & 1 & 1 & 1 & 1 & 1 & 1 & & & 1 & 1 & 1 & 1 & & & & 1 & \\
\hline & 2 & $5-10$ & & & & & & & & 2 & 2 & & & & & 2 & 2 & 2 & & 2 \\
\hline & 3 & $10-20$ & & & & & & & & & & & & & & & & & & \\
\hline & 4 & $20-47$ & & & & & & & & & & & & & & & & & & \\
\hline & 5 & $>47$ & & & & & & & & & & & & & & & & & & \\
\hline \multirow{4}{*}{ Solo/Geologia } & Peso & $\begin{array}{c}\text { Dados } \\
\text { (qualidade) }\end{array}$ & & & & & & & & & & & & & & & & & & \\
\hline & 1 & $\begin{array}{l}\text { Terras boas } \\
\text { para plantar }\end{array}$ & & & & & & & & 1 & 1 & & & 1 & 1 & & & & 1 & 1 \\
\hline & 2 & $\begin{array}{l}\text { Terras } \\
\text { regulares }\end{array}$ & 2 & 2 & 2 & 2 & 2 & 2 & 2 & & & 2 & 2 & & & 2 & 2 & 2 & & \\
\hline & 3 & $\begin{array}{c}\text { Terras } \\
\text { Inadequadas }\end{array}$ & & & & & & & & & & & & & & & & & & \\
\hline \multirow{4}{*}{$\begin{array}{l}\text { Potencial Natural de } \\
\text { Erosão (PNE) }\end{array}$} & Peso & Dados $(\%)$ & & & & & & & & & & & & & & & & & & \\
\hline & 1 & $\begin{array}{l}\text { Baixo risco de } \\
\text { erosão }\end{array}$ & 1 & 1 & 1 & 1 & 1 & & & & & 1 & & 1 & 1 & & 1 & 1 & 1 & 1 \\
\hline & 2 & $\begin{array}{l}\text { Médio risco } \\
\text { de erosão }\end{array}$ & & & & & & 2 & 2 & 2 & 2 & & 2 & & & 2 & & & & \\
\hline & 3 & $\begin{array}{l}\text { Alto risco de } \\
\text { erosão }\end{array}$ & & & & & & & & & & & & & & & & & & \\
\hline \multirow[t]{3}{*}{ Mecanização } & Peso & $\begin{array}{c}\text { Dados } \\
\text { (sim/não) }\end{array}$ & & & & & & & & & & & & & & & & & & \\
\hline & 2 & Sim & 2 & 2 & 2 & 2 & 2 & 2 & 2 & 2 & 2 & 2 & 2 & 2 & 2 & & & 2 & 2 & 2 \\
\hline & 1 & Não & & & & & & & & & & & & & & 1 & 1 & & & \\
\hline \multirow{3}{*}{ Área Agrícola } & Peso & Dados (\%) & & & & & & & & & & & & & & & & & & \\
\hline & 1 & $<50$ & & & 1 & & & & & & & & & & & 1 & 1 & & & \\
\hline & 2 & $>50$ & 2 & 2 & & 2 & 2 & 2 & 2 & 2 & 2 & 2 & 2 & 2 & 2 & & & 2 & 2 & 2 \\
\hline \multirow{4}{*}{$\begin{array}{l}\text { Densidade } \\
\text { Populacional }\end{array}$} & Peso & $\begin{array}{c}\text { Dados } \\
\left(\text { hab km }^{-1}\right)\end{array}$ & & & & & & & & & & & & & & & & & & \\
\hline & 1 & $<15$ & 1 & 1 & 1 & 1 & 1 & 1 & 1 & 1 & & & & & & 1 & 1 & 1 & 1 & 1 \\
\hline & 2 & $15-30$ & & & & & & & & & 2 & 2 & 2 & 2 & 2 & & & & & \\
\hline & 3 & $>30$ & & & & & & & & & & & & & & & & & & \\
\hline \multirow{3}{*}{ Pecuarização } & Peso & $\begin{array}{c}\text { Dados } \\
\text { (sim/não) }\end{array}$ & & & & & & & & & & & & & & & & & & \\
\hline & 2 & Sim & & & & & & & & & & & & & & & & & & \\
\hline & 1 & Não & 1 & 1 & 1 & 1 & 1 & 1 & 1 & 1 & 1 & 1 & 1 & 1 & 1 & 1 & 1 & 1 & 1 & 1 \\
\hline \multirow{4}{*}{ Área de Conflito } & Peso & Dados (\%) & & & & & & & & & & & & & & & & & & \\
\hline & 1 & sem conflito & 1 & 1 & 1 & 1 & & & & & 1 & 1 & 1 & 1 & & 1 & 1 & 1 & 1 & 1 \\
\hline & 2 & $<50$ & & & & & 2 & 2 & 2 & 2 & & & & & 2 & & & & & \\
\hline & 3 & $>50$ & & & & & & & & & & & & & & & & & & \\
\hline Somatório Geral & & & 17 & 16 & 15 & 13 & 16 & 17 & 17 & 17 & 16 & 16 & 17 & 15 & 16 & 14 & 14 & 18 & 15 & 14 \\
\hline
\end{tabular}

\footnotetext{
* As demais zonas homólogas (num total de 132) foram analisadas de forma idêntica às demonstradas neste trabalho.
} 
TABELA 2. Determinação dos níveis de degradação ambiental de acordo com a amplitude dos pesos encontrados. Determination of environmental degradation levels in accordance with the scale of weights found.

\begin{tabular}{|c|c|c|c|}
\hline \multicolumn{4}{|c|}{ Determinação dos Níveis de Degradação Ambiental Conforme a Amplitude dos Pontos ou Pesos Encontrados } \\
\hline $\begin{array}{c}\text { Baixo } \\
\leq 13 \text { Pontos } \\
\text { zonas homólogas } \\
\text { encontradas }\end{array}$ & $\begin{array}{c}\text { Moderado } \\
14-16 \\
\text { zonas homólogas encontradas }\end{array}$ & $\begin{array}{c}\text { Acentuado } \\
17 \text { - } 19 \\
\text { zonas homólogas encontradas }\end{array}$ & $\begin{array}{c}\text { Severo } \\
\geq 20 \text { Pontos } \\
\text { zonas homólogas } \\
\text { encontradas }\end{array}$ \\
\hline $4 ; 25 ; 27 ; 50$ & $\begin{array}{l}1 ; 2 ; 3 ; 6 ; 5 ; 8 ; 9 ; 10 ; 11 ; 12 ; 13 ; 14 ; \\
15 ; 17 ; 18 ; 19 ; 20 ; 21 ; 22 ; 23 ; 26 ; 29 \\
30 ; 31 ; 32 ; 33 ; 35 ; 36 ; 39 ; 43 ; 44 ; 45 ; \\
46 ; 47 ; 51 ; 52 ; 53 ; 54 ; 56 ; 57 ; 58 ; 60 ; \\
68 ; 73 ; 75 ; 76 ; 77 ; 79 ; 80 ; 82 ; 83 ; 84 ; \\
85 ; 88 ; 89 ; 90 ; 93 ; 94 ; 95 ; 97 ; 99 ; \\
100 ; 101 ; 103 ; 104 ; 105 ; 109 ; 111 ; \\
112 ; 113 ; 114 ; 115 ; 116 ; 117 ; 118 \\
126 ; 127 ; 128 ; 130 ; 132 .\end{array}$ & $\begin{array}{l}7 ; 16 ; 24 ; 28 ; 34 ; 37 ; 38 ; 40 ; 41 ; 42 ; 48 \\
49 ; 55 ; 59 ; 61 ; 62 ; 63 ; 64 ; 65 ; 66 ; 67 ; 69 \\
70 ; 71 ; 72 ; 74 ; 78 ; 81 ; 86 ; 87 ; 91 ; 92 ; 96 \\
98 ; 102 ; 106 ; 108 ; 120 ; 121 ; 122 ; 125 ; \\
131 .\end{array}$ & $\begin{array}{l}21 ; 107 ; 110 ; \\
119 ; 123 ; 124 ; \\
129 .\end{array}$ \\
\hline
\end{tabular}

\section{Análise metodológica}

CANDIDO et al. (2002), no Seridó Paraibano, mostram que aproximadamente $50 \%$ da área de estudo apresentaram o índice de degradação "grave" (precisamente 44,86\%), observando-se, ainda, a existência de pequenas áreas com o índice "muito grave" de degradação ambiental (2,24\% do total). Provavelmente, são áreas onde estão formando-se os chamados "núcleos de desertificação". A metodologia adotada neste trabalho é idêntica à de CANDIDO et al. (2002), porém com alguns ajustes e adaptações à região de estudo, especialmente em função dos dados disponíveis.

Apesar de a metodologia ter a sua origem nos estudos da desertificação (regiões semiáridas), a sua adoção na avaliação da degradação das terras no triângulo mineiro, região com clima e solo bastante diferentes, a sua aplicação mostrou-se prática e eficaz para essa nova abordagem.

BAUMGRATZ \& BOAVENTURA (1986), em estudos sobre desertificação realizados nas bacias dos Rios Abaeté, Borrachudo e Indaiá, localizadas no centro-oeste do Estado de Minas Gerais, definiram três níveis para classificar a intensidade da desertificação: 1 a 7, baixa intensidade; 8 a 14, média; 15 a 21, alta. Esses valores (pesos) foram definidos em função dos indicadores ou parâmetros adotados, sendo 21 pontos o máximo atingível por área analisada (Tabela 3).

TABELA 3. Modelo para avaliação de intensidade da desertificação em áreas não urbanizadas. Model for the evaluation of desertification intensity in non-urbanized areas (BAUMGRATZ \& BOAVENTURA, 1986).

\begin{tabular}{|c|c|c|c|c|c|}
\hline \multirow{2}{*}{\multicolumn{2}{|c|}{ Indicadores Diretos }} & \multicolumn{3}{|c|}{ Grau de Manifestação } & \multirow{2}{*}{$\begin{array}{l}\text { Valores } \\
\text { Individuais }\end{array}$} \\
\hline & & 3 & 2 & 1 & \\
\hline \multirow{4}{*}{ 䓂 } & Degradação da cobertura vegetal & $\mathrm{x}$ & & & 3 \\
\hline & Rarefação da fauna alada & & & $\mathrm{x}$ & 1 \\
\hline & Rarefação da fauna terrestre & & & $\mathrm{x}$ & 1 \\
\hline & Rarefação da fauna aquática & & & $\mathrm{x}$ & 1 \\
\hline \multirow{4}{*}{ 苍 } & Poluição do ar & - & - & - & - \\
\hline & Degradação dos recursos hídricos & & $\mathrm{x}$ & & 2 \\
\hline & Degradação dos solos & $\mathrm{x}$ & & & 3 \\
\hline & Total & 6 & 2 & 3 & 11 \\
\hline
\end{tabular}


De acordo com os dados encontrados na Tabela 3 (11 pontos), a intensidade da desertificação foi classificada como média.

Comparando os processos metodológicos adotados, destacam-se algumas melhorias aplicadas neste estudo (avaliação da degradação ambiental da bacia do Rio Uberaba) na ampliação e na diversidade dos parâmetros, e no seu detalhamento, em especial, por permitir a realização de trabalhos em escala de semidetalhe.

FERREIRA et al. (1994) utilizaram grande diversidade de parâmetros, em que a análise de cada parâmetro é baseada na sua presença ou ausência na microrregião estudada. Porém, neste trabalho, os parâmetros foram subdivididos, aumentando assim a sua capacidade de obter informações do ambiente; no entanto, houve redução na sua quantidade, oriundas da ausência de dados ou adaptações da metodologia na região de estudo.

FERNANDES et al. (2005), por meio de análise estatística multivariada, determinaram índices de degradação ambiental (ID) para o Estado de Minas Gerais. A construção dos IDs levou em consideração quatro indicadores: um biológico, dois econômicos e um demográfico. O biológico foi associado à cobertura vegetal. Os dois indicadores econômicos foram definidos pela produtividade das lavouras e dos animais. O indicador demográfico relacionou-se à capacidade das áreas com lavouras (perenes e temporárias) e pastagens (naturais e plantadas) suportarem maior contingente de trabalhadores nas atividades agropecuárias.

Pelos resultados encontrados, verifica-se que Minas Gerais possui índice de degradação (ID) médio de $86 \%$, destacando-se que mais de $40 \%$ de seus municípios obtiveram valores do ID iguais a 1; os demais apresentaram-se acima de 0,70; significando 70\% do território degradado. As exceções ocorreram nos municípios de Senador Amaral e Bom Repouso, que obtiveram IDs mínimos de 0,04 e 0,10, respectivamente.

Analisando o mapa de "estratificação do índice de degradação ambiental", apresentado no estudo realizado por FERNADES et al. (2005), a região do triângulo mineiro (área da bacia do Rio Uberaba) apresenta ID variando entre $87,51 \%$ a $100 \%$. Os níveis de degradação ambiental apresentados neste trabalho (moderado 46,97\%; acentuado 47,96\%, e severo $4,10 \%$ ) somados, correspondem a 99,03\% de degradação ambiental, demonstrando compatibilidade nos resultados.

\section{Análise da bacia do Rio Uberaba}

O mapa apresentado na Figura 9 permitiu definir quatro classes de degradação ambiental e sua distribuição espacial. Nessas áreas, foram encontrados os seguintes percentuais de áreas degradadas:

1 - Áreas com nível de degradação ambiental baixo correspondem a apenas 0,97\%, representando $23,44 \mathrm{~km}^{2}$ de áreas preservadas;

2 - Áreas com nível de degradação ambiental moderado possuem extensão de $1.136,19 \mathrm{~km}^{2}$, correspondendo a $46,97 \%$;

3 - Áreas com nível de degradação ambiental acentuado ocupam a maior extensão da bacia, $1.160,28 \mathrm{~km}^{2}$, correspondendo 47,96\%;

4 - Áreas com nível de degradação ambiental severo possuem extensão de $99,13 \mathrm{~km}^{2}$, correspondendo a $4,10 \%$ de toda a área da bacia. 


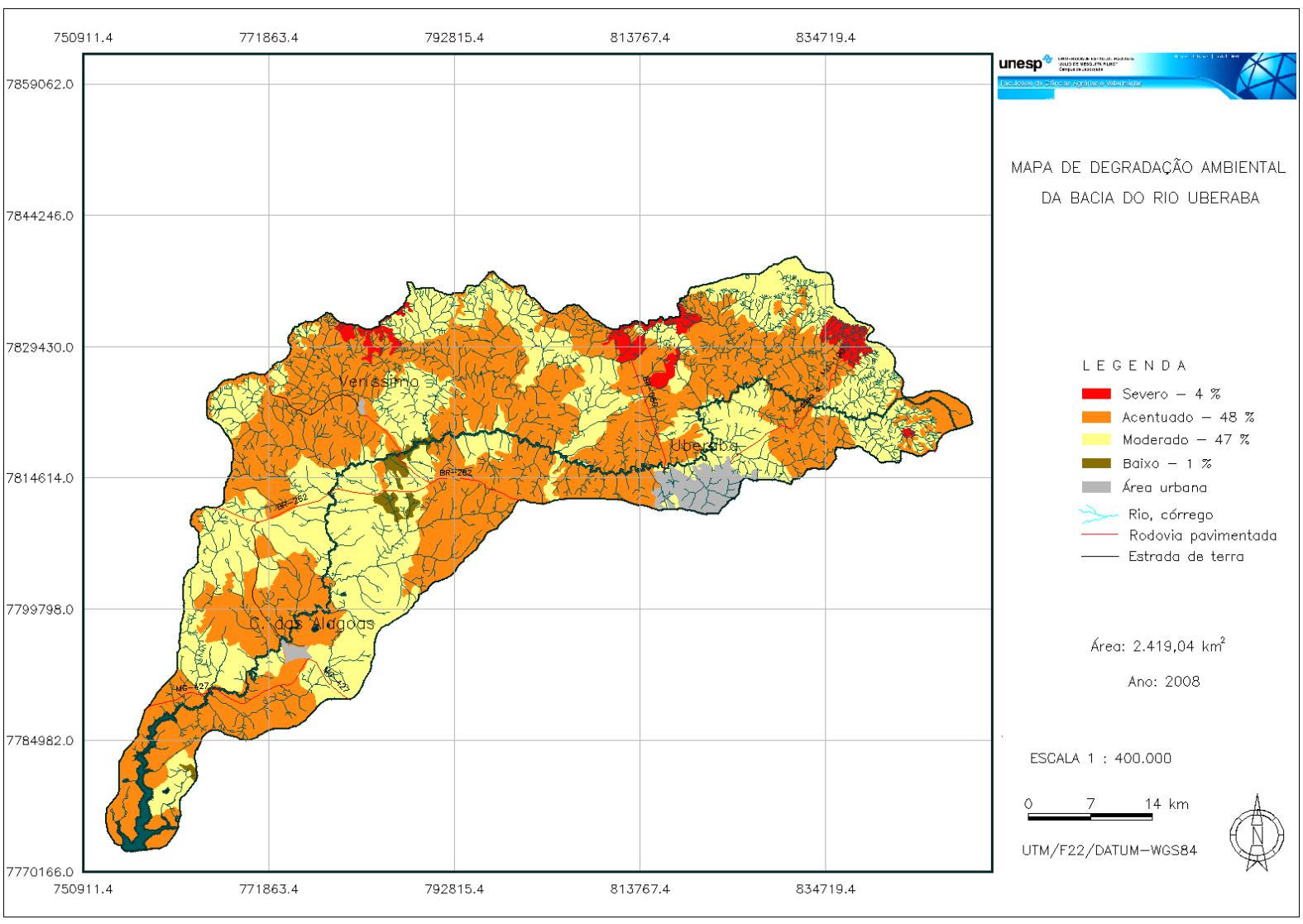

FIGURA 9. Mapa de degradação ambiental da bacia do Rio Uberaba. Environmental degradation map of the Uberaba River basin.

\section{CONCLUSÕES}

Os processos de degradação ambiental, em níveis acentuado e severo juntos, representam $52 \%$ de toda a extensão da bacia, inclusive atingindo áreas protegidas por lei, necessitando de ações imediatas, tanto dos produtores rurais como do poder público, a fim de repensar o modelo atual de exploração das terras e a adoção de técnicas de recuperação dessas áreas.

As áreas classificadas com nível baixo de degradação ambiental possuem extensão inexpressiva, demonstrando modelo de exploração não sustentável da bacia.

As áreas com nível de degradação ambiental severo correspondem apenas a $4 \%$ de toda a bacia, porém são indícios ou sinais de extenuação dos recursos naturais.

A metodologia adotada neste estudo tornou viável a avaliação da degradação ambiental da bacia do Rio Uberaba, permitindo um processo de análise prático e eficaz.

\section{REFERENNCIAS}

BARBOSA, M.P.; MORAES NETO, J.M. de; FERNANDES, M.F.; SILVA, M.J. da. Estudo da degradação das terras: município de Picos. In: SIMPÓSIO BRASILEIRO DE SENSORIAMENTO REMOTO, 8., 2007, Florianópolis. Anais... Florianópolis: Instituto Nacional de Pesquisas Espaciais, 2007. p.4.357-4.363.

BAUMGRATZ, S.S.; BOAVENTURA, R.S. Erosão acelerada e desertificação em Minas Gerais. In: SEMINÁRIO SOBRE DESERTIFICAÇÃO NO NORDESTE, 1986, Recife. Documento final... Brasília: SEMA, 1986. p.84-110. 
CANDIDO, H.G.; BARBOSA, M.P.; SILVA, M.J. da. Avaliação da degradação ambiental de parte do Seridó Paraibano. Revista Brasileira de Engenharia Agrícola e Ambiental, Campina Grande, v.6, n.2, p.368-371, 2002.

CBERS-2 CCD. São José dos Campos: Instituto Nacional de Pesquisas Espaciais, 2007. imagem de satélite. Bandas 2, 3, 4 e composição colorida B2-R3-G4. Escala 1:100.000.

CRUZ, L.B.S. Diagnóstico ambiental da bacia hidrográfica do Rio Uberaba - MG. 2003. 182 f. Tese (Doutorado em Água e Solo) - Faculdade de Engenharia Agrícola, Universidade Estadual de Campinas, Campinas, 2003.

EMBRAPA. EMPRESA BRASILEIRA DE PESQUISA AGROPECUÁRIA. Zoneamento das áreas em processo de degradação ambiental no trópico semiárido do Brasil. Brasília, 1994. Não paginado.

FEOLI, E.; VUERICH, L. G.; ZERIHUN, W. Evaluation of environmental degradation in northern Ethiopia using GIS to integrate vegetation, geomorphological, erosion and socio-economic factors. Elsevier, Philadelphia, v. 91, p.313-325, 2002. Disponível em:

$<\mathrm{http}$ ://www.elsevier.com/locate/agee>. Acesso em: 10 maio 2008.

FERNANDES, E.A.; CUNHA, N.R.S.; SILVA, R.G. da. Degradação ambiental no Estado de Minas Gerais. RER, Rio de Janeiro, v.43, n.1, p.179-198, 2005.

FERREIRA, D.G.; RODRIGUES, V.; MELO, H.P.; RODRIGUES NETO, F.R.; NASCIMENTO, P.J.S. do. Avaliação do quadro da desertificação no Nordeste do Brasil: diagnósticos e perspectivas. Teresina: UFPI/Núcleo DESERT, 1994. 22 p.

ITDG. INTERMEDIATE TECHNOLOGY DEVELOPMENT GROUP. Propuesta metodológica para el analisis de vulnerabilidad en la region San Martín, Peru. Lima, 1994. Não paginado.

ROCHA, J.S.M. da.; KURTZ, S.M.J. M. Manejo integrado de bacias hidrográficas. 4. ed. Santa Maria: Edições UFSM CCR/UFSM, 2001. 302 p.

SÁ, I.B.; SÁ, I.I.S.; SILVA, A.S. Desertificação na região de Cabrobó - PE: a realidade vista do espaço. In: SIMPÓSIO REGIONAL DE GEOPROCESSAMENTO E SENSORIAMENTO

REMOTO, 3., 2006, Aracaju. Anais...Aracaju: Empresa Brasileira de Pesquisa Agropecuária, 2006. Disponível em: <http://www.cpatc.embrapa.br/labgeo/srgsr3/artigos_pdf/038_t.pdf >. Acesso em: 20 jan. 2008.

TORRES, J.L.R.; BARRETO, A.C.; PAULA, J.C. de. Capacidade de uso das terras como subsídio para o planejamento da microbacia do córrego Lanhoso, em Uberaba - MG. Caminhos de Geografia, Uberlândia, v.8, n.24, p.22-32, 2007.

VALLE JÚNIOR, R.F. do. Diagnóstico de áreas de risco de erosão e conflito de uso dos solos na bacia do rio Uberaba. 2008. 222 f. Tese (Doutorado em Produção Vegetal) - Faculdade de Ciências Agrárias e Veterinárias, Universidade Estadual Paulista "Júlio de Mesquita Filho", Jaboticabal, 2008.

VENEZIANI, P.; ANJOS, C.E. dos. Metodologia de interpretação de dados de sensoriamento remoto e aplicações em geologia. São José dos Campos: INPE, 1982. 54 p. 